\title{
To love, wisdom, and the personal in practice
}

\section{Sandy Goldbeck-Wood}

Editor-in-Chief, Journal of Family Planning and Reproductive Health Care, Faculty of Sexual \& Reproductive Healthcare, London, UK

\section{Correspondence to} Dr Sandy Goldbeck-Wood, Journal of Family Planning and Reproductive Health Care, Faculty of Sexual \& Reproductive Healthcare, 27 Sussex Place, London NW1 4RG, UK: goldbeckwood@doctors.org.uk

Received 6 June 2016 Accepted 6 June 2016

CrossMark

To cite: Goldbeck-Wood S. J Fam Plann Reprod Health Care 2016:42:167.
This issue of the journal sees the launch of two new sections. First, we offer a new smørgasbord of snippets of sexual health literature, offered by Venus (see page 236), ${ }^{1}$ named for the Roman goddess of love. Inspired by Minerva, Roman goddess of wisdom and author of an eponymous section in the BMJ, Venus will search the medical literature each quarter, looking for what she thinks a busy sexual health clinician might wish they had had time to read elsewhere.

Tradition has it that Venus was, for better and worse, less armoured and more open than Minerva - more seductive, some might say. There was a certain incident with Paris's apple, a moment of questionable judgment on that gentleman's part in which he chose Venus over Minerva and lived to regret it. So particular thanks to the BMJ's Minerva for welcoming Venus ${ }^{2}-$ a truly gracious gesture, all things considered. However, noting her declaration of competing interests, ${ }^{3}$ we remain confident our Venus will prove no mere 'hussy' rather, a sage lady with binocular vision, one eye roving over the quirky and the not-strictly-serious, while the other keeps a sharp lookout for emerging evidence.

If Venus is a distiller of external evidence, the writer of our other new section, Abi Berger, is an explorer of internal evidence - the kind that is often hidden or unacknowledged. An experienced general practitioner and writer, Abi will explore the personal in practice in a new regular column entitled Person in Practice (see page 225). ${ }^{4}$ Abi offers clinical reflections which incorporate her own experience.

Challenging? It's not hard to see how it might be: for most of us, personal experience was something we learnt to set aside during training. Biomedicine prioritises empirically gathered, objectively measurable data, and evidence-based medicine has enshrined this in standardised methods of evaluation and use of knowledge, resulting in greater uniformity and decreased recognition for the place of intuition, creativity and uncertainty. ${ }^{5}$ But in the real, relational world of clinical practice our ages, genders, nationalities, cultural backgrounds, consciousness-shaping experiences, past and present illnesses and, whisper it, feelings, also impact our practice.

So in Person in Practice, Abi stands up against what we might call 'unopposed objectivity'. She delivers an experiencebased reminder that the clinician can be part of the treatment, ${ }^{6}$ the line between clinician and patient is sometimes more blurred than medical culture has allowed us to recognise, and that reflection is a more useful approach to this intersubjectivity, than denial. So thanks to Abi for disturbing us a little. And to Venus for the evidence-smørgasbord. Oh, and that business with Paris's apple? At JFPRHC, we understand that passion sometimes has regrettable consequences. We're all in favour of reconciliation between love and wisdom. So cheers, Minerva - and here's to sexual health.

Competing interests None declared.

Provenance and peer review Commissioned; externally peer reviewed.

\section{REFERENCES}

1 Anonymous. Venus. J Fam Plann Reprod Med 2016;42:236.

2 Anonymous. Minerva. Venus and reproductive health. BMJ 2016;353:i2855.

3 Anonymous. Minerva. Non-financial COIs. BMJ 2016;353.

4 Berger A. Personal reflections on the menopause journey. J Fam Plann Reprod Med 2016;42:225.

5 Greenhalgh T, Howick J, Maskrey N, Evidence Based Medicine Renaissance Group. Evidence based medicine: a movement in crisis? BMJ 2014;348:g3725.

6 Balint J. The Doctor, His Patient and The Illness (2nd edn). London, UK: Churchill Livingstone, 2000. 